\title{
MÔ HİNH ỨNG DỰG CÔNG NGHỆ HỖ TRỢ XÂY DỰNG PHƯƠNG ÁN QUY HOẠCH SỦ DỤNG ĐẤT
}

\author{
Nguyễn Đắc Nhẫn ${ }^{1}$, Thái Thị Quỳnh Như², \\ Tạ Thị Hà², Đàm Thị Mai Oanh²
}

Tóm tắt: Mô hình ưng dụng công nghệ hỗ trợ xây dụng phương án quy hoạch sử dụng đất nhằm giúp các địa phương lập quy hoạch sủ dụng đất thời kỳ 2021-2030 có chất lượng, đảm bảo tính khả thi, đáp ưng yêu cầu sủ dụng đất đai hiệu quả, bền vũng trong điều kiện biến đổi khi hậu và nước biển dâng. Kết quả nghiên cứu đã đề xuất quy trình ứng dụng công nghệ hỗ trợ việc xây dưng phưong án quy hoạch sư dụng đất, trong đó có phần mềm ứng dụng công nghệ hố trọ việc xây dưng phương án quy hoạch sủ dụng đất phù hợp với tình hình thực tế của địa phưong, đảm bảo tính khả thi.

Từ khóa: Mô hình úng dụng công nghệ, Quy hoạch sử dụng đất.

Ban Biên tập nhận bài: 12/04/2019 Ngày phản biện xong: 08/6/2019 Ngày đăng bài: 25/06/2019

\section{1. Đặt vấn đề}

Hiện nay, việc ứng dụng khoa học công nghệ tiên tiến trong công tác quản lý sử dụng đất đã được thực hiện tại nhiều nước trên thế giới, các phần mềm chuyên dụng phục vụ công tác quản lý sử dụng đất rất có hiệu quả. Việc tiếp thu, chọn lọc, ứng dụng những kinh nghiệm quốc tế trong việc ứng dụng các công nghệ tiến tiến trên thế giới sẽ góp phần nâng cao năng lực quản lý nhà nước ngành Quản lý đất đai theo hướng hiện đại. Với mục tiêu nâng cao chất lượng, tính khả thi của phương án quy hoạch sử dụng đất thì việc ứng dụng công nghệ trong công tác quy hoạch sử dụng đất là cần thiết. Chính vì vậy, trong khuôn khổ của đề tài nghiên cứu khoa học cấp nhà nước "Nghiên cứu cơ sở khoa học, đề xuất đổi mới phương pháp luận và ứng dụng công nghệ trong công tác quy hoạch, kế hoạch sử dụng đất nhằm góp phần quản lý, sử dụng tài nguyên đất hiệu quả, bền vững”, nhóm nghiên cứu đã nghiên cứu xây dựng "Mô hình ứng dụng công nghệ hỗ trợ xây dựng phương án quy hoạch sử dụng đất"; đây là việc làm cần thiết có ý nghĩa thiết thực đối với các địa phương để lập quy

${ }^{1}$ Cuc quy hoạch đất đai

2Viện Nghiên cứu quản lý đất đai

Email:ndnhan@monre.gov.vn;

hagiahung05@gmail.com hoạch sử dụng đất thời kỳ 2021-2030 có chất lượng, đảm bảo tính khả thi nhằm sử dụng đất đai hiệu quả, bền vững trong điều kiện biến đổi khí hậu và nước biển dâng.

Với phương pháp ứng dụng công nghệ GIS, các mô hình toán và các phần mềm chuyên dụng trong các bước lập phương án quy hoạch sử dụng đất. Mô hình ứng dụng công nghệ hỗ trợ xây dựng phương án quy hoạch sử dụng đất đảm bảo kịp thời cập nhật biến động đất đai, tính toán số liệu diện tích chuyển mục đích sử dụng đất, thu hồi đất trong phương án quy hoạch sử dụng đất, nâng cao tính khả thi của phương án quy hoạch sử dụng đất.

\section{Phương pháp nghiên cứu}

- Phương pháp thu thập tài liệu, số liệu thứ cấp: các tài liệu thu thập ở các cơ quan trung ương và địa phương bao gồm các báo cáo, số liệu, tài liệu của các ngành, lĩnh vực có liên quan.

- Phương pháp điều tra, thu thập số liệu sơ cấp: các bảng hỏi, tài liệu điều tra, phân tích, xác định định hướng sử dụng đất theo từng loại đất, phù hợp với mục đích và nhu cầu sử dụng của các ngành, lĩnh vực.Điều tra các thông tin, số liệu tài liệu, bản đồ có liên quan trong lập quy hoạch sử dụng đất tại địa bàn thử nghiệm.

- Phương pháp mô hình hóa: Nhóm nghiên cứu đã tìm ra các đối tượng mà quy hoạch sử 
dụng đất hướng tới, bao gồm các loại đất, các lớp thông tin dữ liệu, bản đồ...phân tích sự tác động các mối liên kết để đưa ra mô hình phù hợp.

- Phương pháp thực nghiệm khoa học: Sau khi mô hình hóa việc lập quy hoạch kế hoạch sử dụng đất có ứng dụng công nghệ thì đưa vào thử nghiệm mô hình cấp tỉnh tại Nam Định và cấp huyện tại huyện Hải Hậu tỉnh Nam Định.

- Phương pháp kế thừa: Kế thừa và phát triển phần mềm của đề tài khoa học cấp bộ và mô hình hỗ trợ lập quy hoạch sử dụng đất của dự án triển khai tại Viện Nghiên cứu quản lý đất đai.

- Phương pháp chuyên gia: Là phương pháp sử dụng trí tuệ của đội ngũ chuyên gia để xem xét nhận định bản chất của đối tượng, tìm ra một giải pháp tối ưu.

- Phương pháp MCA: Phân tích đa chỉ tiêu được sử dụng để đánh giá các vùng không gian phù hợp với một mục đích sử dụng và được sử dụng để so sánh các phương án quy hoạch.

- Phương pháp tối ưu tuyến tính: Được sử dụng để tính toán diện tích tối ưu của một số loại đất theo các ràng buộc kèm theo.

\section{Kết quả nghiên cứu và thảo luận}

3.1. Mô hình úng dung công nghệ hỗ trọ' việc xây dụng phương án quy hoạch sử dụng đất

\subsubsection{Phạm vi của mô hình}

Trong quy trình lập quy hoạchsử dụng đất gồm các hạng mục công việc, như: Điều tra, thu thập thông tin, tài liệu; Phân tích, đánh giá điều kiện tự nhiên, kinh tế - xã hội và môi trường tác động đến việc sử dụng đất; Phân tích, đánh giá tình hình quản lý, sử dụng đất, kết quả thực hiện quy hoạch sử dụng đất kỳ trước; Đánh giá tiềm năng đất đai và xây dựng định hướng sử dụng đất cho 20 năm; Xây dựng phương án quy hoạch sử dụng đất cho 10 năm; Xây dựng báo cáo thuyết minh tổng hợp, hệ thống bản đồ và các tài liệu có liên quan; Thẩm định, phê duyệt quy hoạch sử dụng đất.

Trong phạm vi của đề tài, việc ứng dụng công nghệ được thực hiện hỗ trợ trong hạng mục công việc xây dựng phương án quy hoạch sử dụng đất, bao gồm các nội dung sau:

- Lựa chọn vị trí tối ưu đối với một số loại đất, tính toán hiệu quả phương án quy hoạch sử dụng đất tối ưu.

- Tính toán nhu cầu sử dụng đất và hỗ trợ trích xuất hệ thống biểu quy hoạch theo quy định;

- Xây dựng và trích xuất bản đồ quy hoạch sử dụng đất, bản đồ chuyên đề, bản đồ định hướng sử dụng đất theo đúng quy phạm về bản đồ;

3.1.2. Yêu cầu thông tin đầu vào của mô hình

Để có thể ứng dụng được công nghệ hỗ trợ xây dựng phương án quy hoạch sử dụng đất thì thông tin, dữ liệu đầu vào phải đáp ứng được các yêu cầu thông tin đầu vào gồm nhóm dữ liệu thuộc tính và dữ liệu không gian; đảm bảo mối quan hệ topology giữa các đối tượng.

3.1.3. Đề xuất quy trình úng dụng công nghệ hỗ trọ việc xây dựng phương án quy hoạch sủ dụng đất

Trên cơ sở nghiên cứu khoa học và thực tiễn, nhóm nghiên cứu đề xuất quy trình ứng dụng công nghệ hỗ trợ việc xây dựng phương án quy hoạch sử dụng đất trong đó có thiết kế phần mềm ứng dụng công nghệ hỗ trợ việc xây dựng phương án quy hoạch sử dụng đất. Quy trình gồm các bước công việc như sau (phụ lục 1):

\section{Bước 1: Thu thập thông tin và chuẩn hóa dĩu liệu đầu vào \\ a) Thông tin dĩ liệu đầu vào}

Tiến hành thu thập và phân loại thông tin, dữ liệu đầu vào theo thuộc tính và không gian:

a1) Nhóm dữ liệu thuộc tính:

- Nhóm thông tin về các chỉ tiêu hiện trạng và định hướng chiến lược phát triển kinh tế, xã hội;

- Nhóm thông tin về tiềm năng đất đai, mức độ thích hợp và các yếu tố hạn chế tác động sử dụng đất;

- Nhóm thông tin về hiện trạng sử dụng đất, biến động đất đai;

- Nhóm thông tin về định mức sử dụng đất và tiến bộ khoa học công nghệ có liên quan đến việc sử dụng đất;

- Nhóm thông tin về các nhu cầu sử dụng một số loại đất đặc thù của địa phương.

a2) Nhóm dữ liệu không gian:

Các dữ liệu không gian cần thu thập bao gồm: bản đồ hiện trạng sử dụng đất, bản đồ quy hoạch 
các ngành, bản đồ hành chính, bản đồ tiềm năng đất đai, bản đồ thổ nhưỡng.

\section{b) Chuẩn hóa dũ liệu đầu vào}

Từ các nguồn bản đồ thu thập được, tiến hành chuyển sang định dạng dữ liệu trong phần mềm GIS và tách các lớp cần thiết, giữ và tạo thêm các trường thuộc tính quan trọng liên quan đến vấn đề đánh giá, đảm bảo mối quan hệ topology giữa các đối tượng.

c) Xây dựng và chuẩn hóa các nhóm lớp thông tin

- Nhóm 1: Nhóm lớp thông tin nền địa lý.

Phần lớn các lớp trong nhóm lớp này sử dụng như yếu tố nền, được sử dụng khi tạo thành bản đồ kết quả hoàn chỉnh.Một số lớp như đường giao thông và thủy hệ sẽ được sử dụng trong các phép phân tích không gian.

- Nhóm 2: lớp dữ liệu khoanh đất theo nguồn gốc phát sinh.

Nhóm lớp này được sử dụng trong các phép phân tích không gian, gán thang điểm cho các khoanh đất dựa theo tiêu chí của chuyên gia đưa ra.

- Nhóm 3: nhóm lớp hiện trạng sử dụng đất.

Nhóm lớp này được sử dụng trong các phép phân tích không gian, gán thang điểm cho các khoanh đất dựa theo tiêu chí của chuyên gia đưa ra. Ngoài ra, lớp này cũng là nguồn dữ liệu để tách những loại đất riêng biệt, phục vụ cho quá trình phân tích không gian.

- Nhóm 4: nhóm lớp dữ liệu các chỉ tiêu phục vụ quy hoạch.

Là nhóm lớp được tách riêng, phục vụ trực tiếp cho quá trình phân tích không gian, gán thang điểm đánh giá các chỉ tiêu.

- Nhóm 5: nhóm lớp dữ liệu chất lượng đất, tiềm năng đất đai.

Là nhóm lớp dữ liệu thể hiện chất lượng đất và tiềm năng đất đai theo mỗi mục đích sử dụng cụ thể.

- Nhóm 6: nhóm lớp dữ liệu về phân hạng đất nông nghiệp.

Là các lớp thông tin về đất, thông tin về địa hình, khí hậu, chế độ nước, độ phì của đất; thông tin kết quả đánh giá chất lượng đất, tổng hợp và phân hạng đất.
- Nhóm 7: nhóm lớp nhu cầu sử dụng đất đến năm 2030, gồm chỉ tiêu sử dụng đất theo $\mathrm{QH}$ cấp trên, đăng ký nhu cầu sử dụng đất của các cấp, các ngành, lĩnh vực và đơn vị hành chính cấp dưới trực tiếp.

\section{d) Thiết kế Geodatabase lưu trũ dũ liệu}

Khuôn dạng dữ liệu trong GIS là Geodatabase (*.gdb), các dữ liệu khi được chuyển vào trong Geodatabase được lưu trữ thành các lớp riêng biệt (Feature Class), phân chia vào trong nhóm lớp (Feature Dataset).

- Cơ sở toán học: Dữ liệu không gian của cơ sở dữ liệu mô hình quy hoạch sử dụng đất sử dụng hệ quy chiếu và hệ tọa độ quốc gia VN2000.

- Elipsoid quy chiếu WGS84 với kích thước: (i) Bán trục lớn: 6378,137m; (ii) Độ dẹt: 298,257223563.

- Lưới chiếu bản đồ: sử dụng lưới chiếu hình trụ ngang đồng góc với múi chiếu $30^{\circ}$ có hệ số điều chỉnh biến dạng chiều dài $\mathrm{k} 0=0,9999$, kinh tuyến trục theo từng địa phương.

- Cấu trúc dữ liệu tổng quát được tổ chức thiết lập và quản lý trong Geodatabase.

Cấu trúc dữ liệu mô hình ứng dụng công nghệ hỗ trợ việc xây dựng phương án quy hoạch sử dụng đất trong môi trường GeoDatabase như sau:

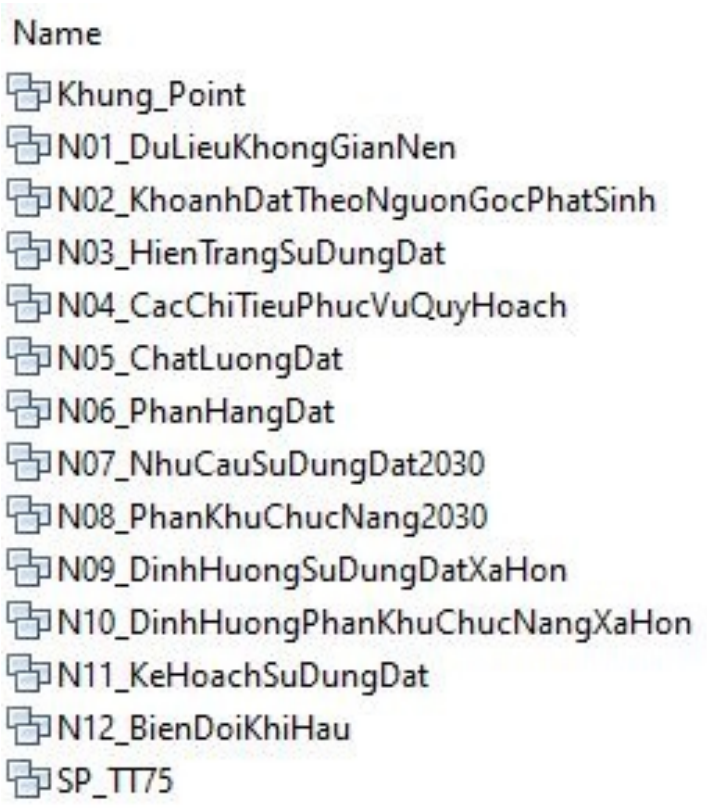

Hình 1. Cấu trúc dũ liệu mô hình ưng dụng công nghẹ 
đ) Kết nối với phần mềm hỗ trợ lập quy hoạch sủ dụng đất

2. Bước 2: Tính toán lựa chọn chồng xếp dĩu liệu không gian để lụa chọn vị trí quy hoạch phù hợp

a) Tính toán lựa chon lớp quy hoạch sủ dụng đất và tiềm năng đất đai

+ Nhóm lớp quy hoạch sử dụng đất (kỳ trước) được sử dụng với mục đích là lớp cơ sở để so sánh, đánh giá với các phương án quy hoạch sử dụng đất (phần kết quả của phần mềm sau quá trình phân tích). Nhóm lớp được thu nhận bằng cách tách các khoanh đất đã khoanh vẽ từ bản đồ khoanh vẽ tại địa phương.

+ Tiềm năng đất đai là lớp thông tin về kết quả đánh giá tiềm năng đất đai.

b) Xây dụng bộ tiêu chí xác định vị trí phù hơp cho các loại đất đã lựa chọn

+ Trên cơ sở tiêu chuẩn, quy chuẩn, định mức đưa ra các mối quan hệ giữa nhu cầu của loại đất cần quy hoạch với các yếu tố kinh tế - xã hội môi trường. Tham khảo ý kiến của các chuyên gia để xây dựng bộ tiêu chí cụ thể cho mỗi loại đất cần quy hoạch.

+ Sử dụng MCA - AHP: Những quyết định thường thấy khó khăn trong xác định định lượng cho các nhóm chỉ tiêu cùng một lúc, do vậy các chuyên gia đánh giá phản ánh ý kiến trong ma trận so sánh cặp (ma trận vuông).

Mỗi phương án sẽ được tính toán và cho điểm. Dựa trên số điểm có được, quyết định cuối cùng sẽ được lựa chọn.

Tuy nhiên, ý kiến chuyên gia trong thực tế sẽ không phải như vậy do họ không bao quát được tính logic của ma trận so sánh. Theo Thomas L. Saaty, có thể sử dụng tỷ số nhất quán của dữ liệu (Consistency Ratio - CR) so sánh mức độ nhất quán với tính khách quan (ngẫu nhiên) của dữ liệu.

Đối với mỗi một ma trận so sánh cấp $n$, đã được thử nghiệm tạo ra các ma trận ngẫu nhiên và tính chỉ số $C I$ trung bình của chúng và gọi là RI - chỉ số ngẫu nhiên. Nếu giá trị tỷ số nhất quán $\mathrm{CR}<0,1$ là chấp nhận được, nếu lớn hơn đòi hỏi người ra quyết định thu giảm sự không đồng nhất bằng cách thay đổi giá trị mức độ quan trọng giữa các cặp chỉ tiêu.

c) Tính trọng số cho các chỉ tiêu

Thuật toán FAHP: Nhóm nghiên cứu đã vận dụng cách tính toán trọng số chỉ tiêu bằng kỹ thuật FAHP. Kỹ thuật này có bốn bước tính toán trọng số chỉ tiêu bằng kỹ thuật FAHP [5], gồm:

Bước 1: Tổng hợp mức độ giá trị mờ đối với đối tượng thứ I;

Bước 2: So sánh cặp số mờ;

Bước 3: Xác định khả năng cho một số mờ lớn hơn số mờ $\mathrm{k}$;

Bước 4: Thông qua việc bình thường hóa, vector trọng số bình thường.

Một bộ thông số hàm mờ gồm tối đa 5 tham số. Chọn một trong số 5 kiểu hàm ở trên cho phù hợp với đặc tính của chỉ tiêu đánh giá. Các giá trị $\mathrm{a}, \mathrm{b}, \mathrm{c}, \mathrm{d}$ : giá trị đặc trưng của các hàm mờ, ý nghĩa của từng tham số đối với từng kiểu hàm được thể hiện trên biểu đồ ở bảng trên. 
Bảng 1. Các kiểu hàm mò̀ trong kỹ thuật FAHP

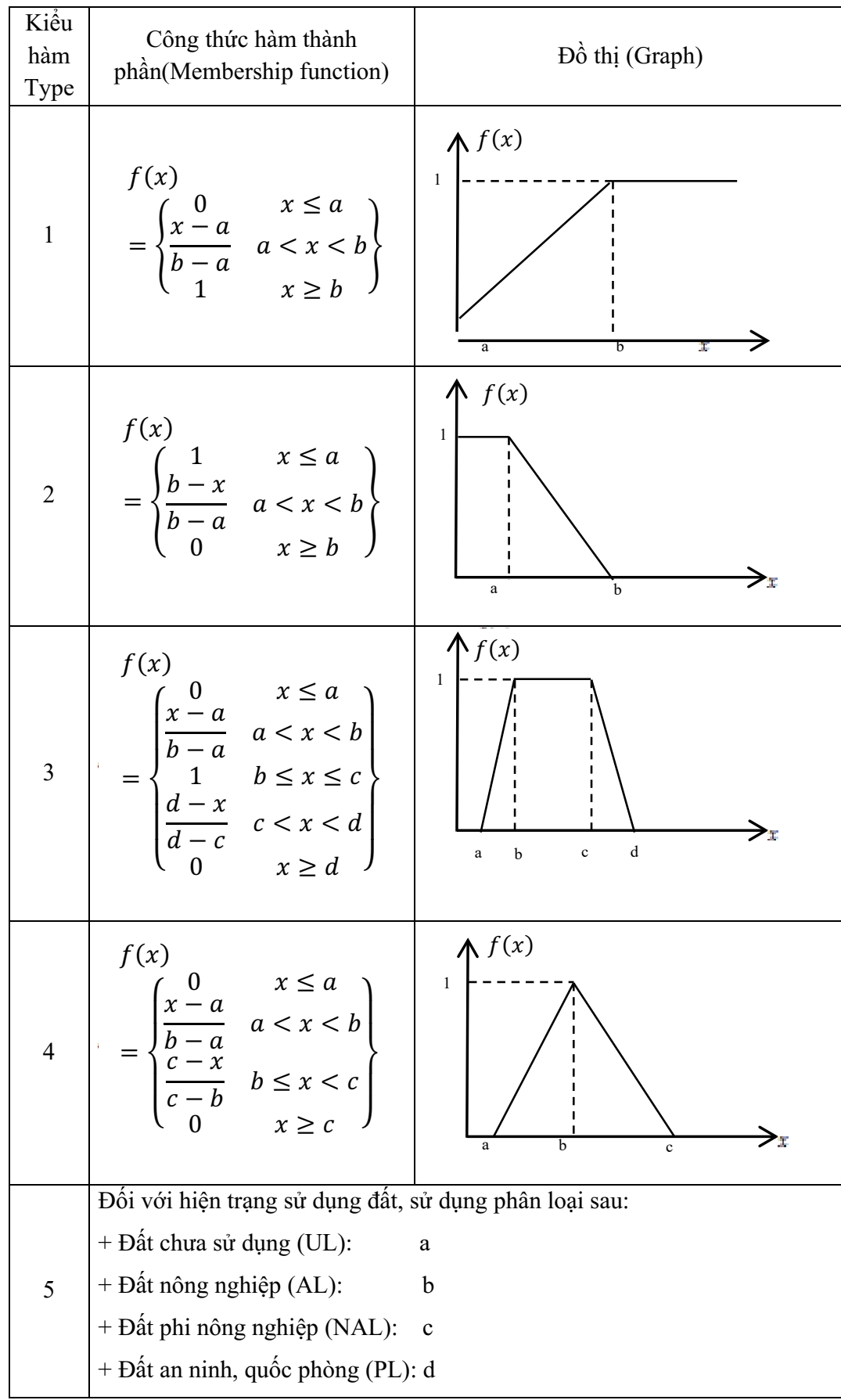

d) Tạo bản đồ đơn tính theo tùng chỉ tiêu

Tạo các lớp polygon/raster thể hiện giá trị đã được phân loại và tính điểm cho mỗi chỉ tiêu như ở trên. Chồng xếp các lớp $\mathrm{BĐ}$ chỉ tiêu: Lớp giá trị thích hợp cho vị trí quy hoạch được tính toán từ việc kết hợp các lớp giá trị đầu vào đã được phân loại và tính điểm ở trên với các trọng số tương ứng của từng lớp chỉ tiêu cụ thể. Nó thể hiện các giá trị từ thấp nhất đến lớn nhất.

$$
S=\sum_{i=1}^{n}\left(W_{i} \times X_{i}\right)
$$

Trong đó $\mathrm{S}$ là chỉ số thích hợp; Wi là trọng số của chỉ tiêu i; n là tổng số chỉ tiêu; Xi là điểm của chỉ tiêu i.

Từ kết quả của bước trên, những vị trí phù hợp cho quy hoạch từng loại đất đã được xác định.

3. Bước 3: Tính toán lựa chọn tổng hợp cân đối dũ liệu nhu cầu sử dụng đất 
a) Tính toán nhu cầu sủ dụng đất

Các chỉ tiêu sử dụng đất được phân nhóm dựa trên phương pháp dự báo và đặc điểm sử dụng.

- Nhóm I: Các loại đất có tính đặc thù như đất quốc phòng; đất an ninh, đất khu công nghiệp, đất khu chế xuất, đất cụm công nghiệp. Xác định theo chỉ tiêu cấp trên phân bố; riêng đất cụm công nghiệp được xác định trên cơ sở kết quả điều tra trực tiếp nhu cầu sử dụng đất tại địa phương.

- Nhóm II: Các loại đất có định mức sử dụng đất như: đất thương mại dịch vụ; đất cơ sở văn hóa, đất cơ sở y tế; đất cơ sở giáo dục - đào tạo; đất cơ sở thể cục thể thao; đất giao thông; đất thủy lợi; đất công trình năng lượng; đất công trình bưu chính viễn thông; đất chợ; đất bãi thải, xử lý chất thải; đất ở tại nông thôn; đất ở tại đô thị; đất xây dựng trụ sở cơ quan; đất làm nghĩa trrang, nghĩa địa; đất sinh hoạt cộng đồng [2]. Phương pháp dự báo theo định mức sử dụng đất, hệ số co giãn đất, hàm mục tiêu [4].

- Nhóm III: Các loại đất ít biến động do quy mô diện tích nhỏ hoặc mang tính đặc thù theo tiềm năng khu vực của từng địa phương: Đất cụm công nghiệp; đất sử dụng cho hoạt động khoáng sản; đất cơ sở nghiên cứu khoa học công nghệ; đất cơ sở dịch vụ về xã hội; đất có di tích lịch sử - văn hóa; đất danh lam thắng cảnh; đất xây dựng trụ sở của tổ chức sự nghiệp; đất xây dựng cơ sở ngoại giao; đất cơ sở tôn giáo; đất sản xuất vật liệu xây dựng, làm đồ gốm, đất cơ sở tín ngưỡng; đất sông, ngòi, kênh rạch, suối; đất có mặt nước chuyên dùng; đất phi nông nghiệp khác. Các loại đất này được xác định bằng phương pháp điều tra số liệu trực tiếp theo nhu cầu thực tế trong kỳ quy hoạch.

b) Xác định nhu cầu sử dụng đất

Từ 3 phương pháp dự báo ta tính toán được nhu cầu sử dụng đất; kết hợp với kết quả chồng xếp các lớp bản đồ chỉ tiêu lựa chọn vị trí cho các loại đất để hỗ trợ xác định nhu cầu sử dụng đất.Thực hiện cân đối giữa nhu cầu xác định được, các chỉ tiêu cấp trên phân bổ với hiện trạng và tiềm năng đất đai thực tế của địa phương.

\section{Bước 4: Xây dụng phương án quy hoạch}

\section{sử dụng đất}

a) Thiết kế lóp Quy hoạch, lựa chọn vị trí không gian phù hơp

Sử dụng phương pháp chuyên gia, cùng với kết quả các vị trí phù hợp cho một số loại đất đã được tính toán ở bước trên, xây dựng 2-3 phương án quy hoạch sử dụng đất. Các phương án quy hoạch này lại tiếp tục được các chuyên gia đánh giá về hiệu quả kinh tế - xã hội - môi trường, đưa ra một phương án quy hoạch sử dụng đất đạt hiệu quả kinh tế - xã hội - môi trường.

b) Tổng hợp nhu cầu sủ dụng đất

Sau khi xác định được nhu cầu sử dụng đất phần mềm sẽ tính toán tổng hợp nhu cầu sử dụng đất theo đơn vị hành chính và cho ra danh mục nhu cầu sử dụng đất.

c) Đánh giá tác động của phuoong án quy hoạch sư dụng đất đến kinh tế, xã hội và môi trưòng

Sau khi có phương án quy hoạch sử dụng đất ta tiến hành đánh giá tác động của phương án quy hoạch sử dụng đất đến kinh tế, xã hội và môi trường [1].

5. Bước 5: Chồng xếp xây dụng bản đồ quy hoạch, kế hoạch sử dụng đất

- Sử dụng phần mềm biên tập theo quy định hiện hành để tạo bản đồ quy hoạch sử đất hoàn chỉnh.trên cơ sở chồng xếp phương án quy hoạch sử dụng đất lên bản đồ hiện trạng sử dụng đất.

- Trích xuất bản đồ quy hoạch sử dụng đất.

- Trích xuất bản đồ kế hoạch sử dụng đất: Dựa trên dữ liệu thuộc tính năm thực hiện của lớp quy hoạch sử dụng đất, phần mềm sẽ tự động xây dựng được bản đồ kế hoạch sử dụng đất trên nền của bản đồ quy hoạch sử dụng đất.

\section{Bước 6: Tính toán xây dụng hệ thống biểu quy hoạch, kế hoạch sử dụng đất}

- Tính toán chu chuyển đất đai: phần mềm sẽ tính toán chu chuyển các loại đất theo thời kỳ quy hoạch.

- Trích xuất hệ thống biểu quy hoạch, kế hoạch sử dụng đất: Trích xuất hệ thống biểu quy hoạch sử dụng đất; từ hệ thống biểu quy hoạch sẽ trích xuất biểu kế hoạch sử dụng đất.

Sơ đồ quy trình ứng dụng công nghệ hỗ trợ 
việc xây dựng phương án quy hoạch sử dụng đất được thể hiện tại Phụ lục 1 kèm theo.

\section{2. Đánh giá chung về phần mềm}

a) Việc ứng dụng phần mềm hỗ trợ xây dựng phương án quy hoạch sử dụng đất cho phép thực hiện hỗ trợ chính các tác nghiệp kỹ thuật, như:

- Đánh giá lựa chọn vị trí không gian phù hợp cho từng loại đất.Áp dụng phương pháp đánh giá đa chỉ tiêu và GIS, tạo ra lớp khoanh vẽ khu vực quy hoạch đã lựa chọn vị trí.

- Chồng xếp hoàn thiện bản đồ quy hoạch, kế hoạch sau đó trích xuất ra định dạng *.DGN theo quy định.

- Tính toán dự báo được nhu cầu một số loại đất theo định mức sử dụng đất, hệ số co giãn đất, hàm mục tiêu.

- Xác định, tổng hợp thực hiện chu chuyển tự động các loại đất theo niên hạn quy hoạch, kế hoạch.

- Trích xuất được hệ thống biểu quy hoạch kế hoạch đã được biên tập chỉnh in theo quy định.

b) Phần mềm ứng dụng đã xây dựng được modul cho việc lập ra nhiều phương án quy hoạch sử dụng đất, đánh giá hiệu quả kinh tế, xã hội, môi trường của từng phương án, so sánh để lựa chọn.

c) Phần mềm ứng dụng cho phép lựa chọn vị trí không gian đã chọn khu vực phù hợp nhất; nhu cầu sử dụng đất cũng đã được tính toán dựa trên cơ sở khoa học, căn cứ vào định mức và được cân đối với nhu cầu thực tế và chỉ tiêu cấp trên phân bổ để xác định nhu cầu sử dụng đất đầy đủ và hợp lý nhất của phương án quy hoạch.

\section{Kết luận}

Với mục tiêu nâng cao chất lượng, tính khả thi của phương án quy hoạch sử dụng đất, nhóm nghiên cứu đã thực hiện công trình nghiên cứu xây dựng Mô hình ứng dụng công nghệ hỗ trợ xây dựng phương án quy hoạch sử dụng đất. Kết quả nhiên cứu đã đề xuất quy trình ứng dụng công nghệ hỗ trợ việc xây dựng phương án quy hoạch sử dụng đất, trong đó có phần mềm ứng dụng công nghệ hỗ trợ việc xây dựng phương án quy hoạch sử dụng đất.

Mô hình ứng dụng công nghệ hỗ trợ xây dựng phương án quy hoạch sử dụng đất với việc thiết kế phần mềm ứng dụng công nghệ hỗ trợ việc xây dựng phương án quy hoạch sử dụng đất sẽ cho phép áp dụng công nghệ tiên tiến vào một số bước quan trọng trong quá trình xây dựng phương án quy hoạch sử dụng đất, nâng cao tính khả thi của phương án quy hoạch sử dụng đất, góp phần sử dụng đất đai hiệu quả, bền vững trong điều kiện biến đổi khí hậu và nước biển dâng.

Lời cảm ơn: Để hoàn thành công trình nghiên cưu này, nhóm nghiên cứu chúng tôi đã nhận được sự giúp đỡ chân thành, nhiệt tình của nhiều co quan, tổ chức; của các chuyên gia, các nhà khoa học và các đồng nghiệp. Nhân dịp này, nhóm nghiên cứu xin trân trọng cảm ơn Văn phòng Chuơng trình KH\&CN cấp quốc gia về TNMT và BĐKH - Bộ Tài nguyên và Môi truòng; Tổng cuc Quản lý đất đai; Sở Tài nguyên và Môi truờng tỉnh Nam Định; Viện Nghiên cứu quản lý đất đai; Cuc Quy hoạch đất đai; các chuyên gia, các nhà nhà khoa họ và các đồng nghiệp đã giúp đỡ chúng tôi trong suốt quá trình nghiên cứu và đã có nhũng đóng góp ý kiến quý báu để nhóm nghiên cứu chúng tôi hoàn thành công trình đạt kết quả như muc tiêu đặt ra. 


\section{BÀI BÁO KHOA HỌC}

\section{Tài liệu tham khảo}

1. Nguyễn Tiến Cường (2009), Nghiên cứu đề xuất phuơng pháp dụ báo diện tích một số đất phi nông nghiệp phục vu quy hoạch sử dụng đất cả nước và các vùng trong mối quan hệ với các chỉ tiêu kinh tế - xã họi, Trung tâm Điều tra quy hoạch đất đai.

2. Bộ Tài nguyên và Môi trường (2015), Luật Đất đai năm 2013 và các văn bản huoóng dẫn thi hành, NXB Nông nghiệp, Hà Nội.

3. Quốc hội nước Cộng hòa xã hội chủ nghĩa Việt Nam (2006), Luật Tiêu chuẩn và Quy chuẩn kỹ thuật, NXB Chính trị quốc gia, Hà Nội.

4. Trần Xuân Miễn (2016), Mô hình dụ báo nhu cầu sủ dụng đất phục vụ xây dụng nông thôn mói trên địa bàn huyện Yên Dũng, tỉnh Bắc Giang, Tạp chí Khoa học Kỹ thuật Mỏ-Địa chất, số 57, 2027.

5. Đoàn Khánh Hoàng (2016), Quá trình phân tích thú bậc mờ (FAHP) và úng dụng trong lĩnh vục GIS, Trường đại học mỏ địa chất.

\section{THE APPLICATION OF TECHNOLOGY FOR LAND USE PLANNING Nguyen Dac Nhan ${ }^{1}$, Thai Thi Quynh Nhu², Ta Thi Ha², Dam Thi Mai Oanh² \\ ${ }^{1}$ Department of Land Planning ${ }^{2}$ Research Institute for Land Management}

Abstract: The application of technology to support the development of land use in the framework "to help localities make planning land use in the period of 2021-2030" shows good quality and feasibility, meeting the requirements of the effective and sustainable land use in terms of climate change and sea level rise. Research results have proposed technology application process to support the development of land use planning including technology application software to support the development of land use planning in accordance with the actual situation of the locality, ensuring the feasibility.

Keywords: Technology application model; Land use planning. 


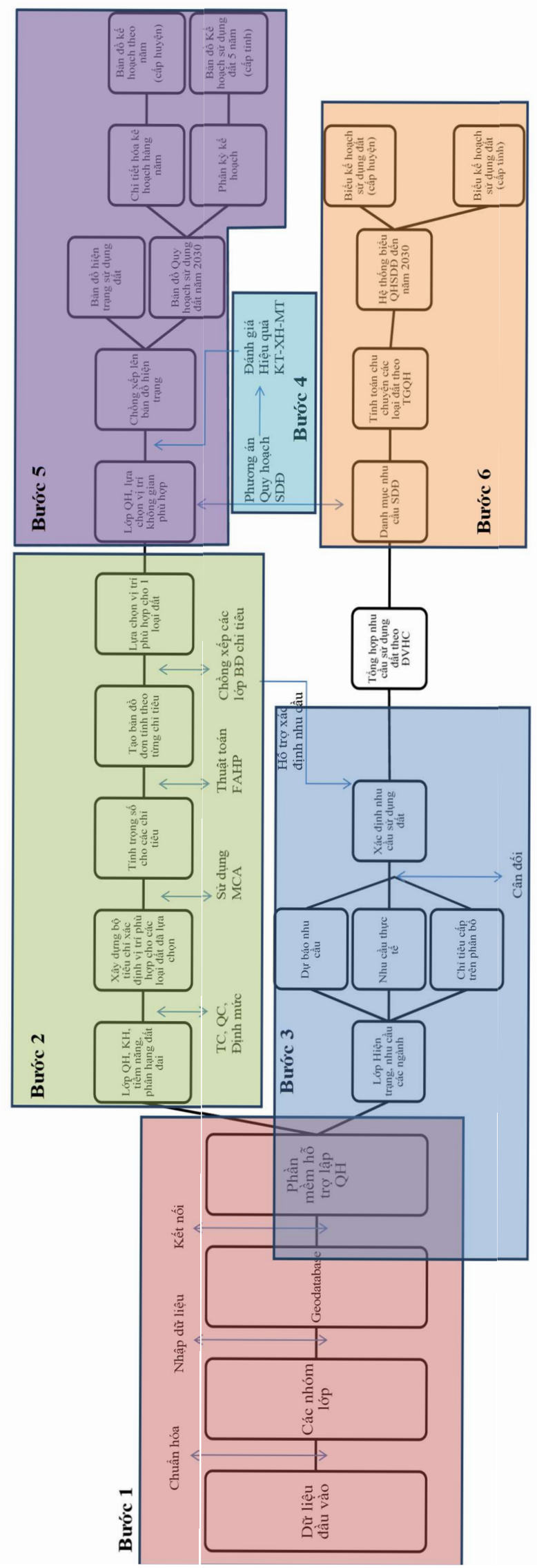

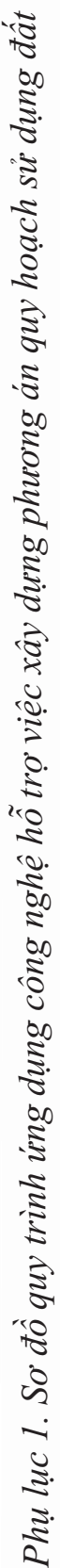

